\title{
Pulsed Doppler echocardiographic evaluation of neonatal circulatory changes
}

\author{
HIROHIKO SHIRAISHI, * MASAYOSHI YANAGISAWA \\ From the Department of Paediatrics, fichi Medical School, Tochigi, fapan
}

SUMMARY Pulsed Doppler echocardiograms were obtained from 42 normal fullterm neonates at $<12$ hours ( 20 subjects), 4 days (20 subjects), and 33 days (12 subjects). The acceleration time of the flow velocity and ventricular systolic time intervals were measured on recordings obtained at the right and left ventricular outflow tract, and the patency of the ductus arteriosus was evaluated by the flow at the pulmonary end of the ductus. The flow velocity pattern of the right ventricular outflow tract changed from a triangular shape with a peak velocity in early systole in the younger age groups to a dome-like contour with a peak velocity in mid-systole; thus the ratio of mean acceleration time to right ventricular ejection time increased with age. The flow velocity pattern of the left ventricular outflow tract was triangular in all age groups, and the ratio of mean acceleration time to left ventricular ejection time showed no significant change with age. The right ventricular pre-ejection period shortened and the right ventricular ejection time lengthened with age; thus the ratio of mean right ventricular pre-ejection period to right ventricular ejection time decreased with age. The left ventricular systolic time intervals showed no significant change with age. The ductus arteriosus was patent in all subjects who were less than 12 hours old but was closed in the older neonates.

Pulsed Doppler echocardiography is a valuable method of evaluating pulmonary vascular bed in the early neonatal period.

Soon after birth the ductus arteriosus and foramen ovale close and there are considerable falls in pulmonary vascular resistance and pulmonary artery pressure. ${ }^{1}$ It would be useful to have a reliable noninvasive method of evaluating these changes. Pulsed Doppler echocardiography has been used to assess blood flow in the heart and great vessels noninvasively, and it has various clinical applications including detection of valvular stenosis or insufficiency and shunt lesions. ${ }^{23}$ The flow velocity pattern of the right ventricular outflow tract has been shown to be useful in assessing the pulmonary vascular resistance and diastolic pressure of the pulmonary artery in patients with congenital heart disease. $^{45}$

To test the hypothesis that the flow pattern of the right ventricular outflow tract might reflect the

Requests for reprints to Dr Hirohiko Shiraishi, Department of Paediatrics, Jichi Medical School, Minamikawachi, Tochigi, 329-04, Japan.

Accepted for publication 29 September 1986 decreasing pulmonary vascular resistance and diastolic pressure of the pulmonary artery in the early neonatal period we studied the normal flow patterns of the right and left ventricular outflow tracts in the first month of life by pulsed Doppler echocardiography.

\section{Subjects and methods}

We examined 42 neonates and infants (estimated gestation 37-41 weeks): $20<12$ hours old ( 0 day old), 20 3-9 days old (4 day old), and 12 28-37 days old ( 1 month old). Ten neonates were examined twice. All infants had uneventful perinatal histories and were normal by physical examinations and by cross sectional echocardiograms. The heart rates of the infants ranged from 90 to 160 beats $/ \mathrm{min}$ at the time of examination and neither arrhythmia nor conduction abnormalities were noted. Informed parental consent was obtained for all subjects before examination.

For pulsed Doppler echocardiography we used an 
Aloka SSD-720 compound ultrasound diagnostic device and a pulsed Doppler transducer (Aloka ASU-32-5), with a carrier frequency of $5.0 \mathrm{MHz}$ and pulse repetition frequency of $8.0 \mathrm{KHz}$. The length of the sample volume was $2 \mathrm{~mm}$. Doppler signals were analysed by fast Fourier transform with an Aloka UGR-23 pulsed Doppler unit, displayed in the form of frequency spectrum, and recorded with an Aloka SSZ-95 strip chart recorder at a paper speed of $100 \mathrm{~mm} / \mathrm{s}$ together with an electrocardiogram and $M$ mode echocardiogram on which the depth of the sample volume was marked. Flow away from the transducer was displayed below the baseline and flow towards the transducer was displayed above the baseline. The time lag in the sample and frequency analysis of Doppler signals has been estimated to be $22-28 \mathrm{~ms}^{6}{ }^{7}$

The transducer was placed at the intercostal space of the left lower sternal border and at the apex to obtain clear parasternal short axis and apical longc axis images. The sample volume was then moved to $\Rightarrow$ just below the semilunar valves at each ventriculare? outflow tract and then to the pulmonary end of the ductus. Care was taken to align the ultrasonic $\overline{\underline{\underline{\sigma}}}$. Doppler beam with the flow in each ventricular? outflow tract. All infants were examined while they $\cong$ were sleeping or resting quietly.

We measured three variables on the spectral records of the pulsed Doppler echocardiograms of the right and left ventricular outflow tracts: these $\vec{\omega}$ were the pre-ejection period (PEP), which was? defined as the time from the $Q$ wave of the electro-? cardiogram to the onset of the ejection flow; the $Y$ acceleration time (AcT), which was defined as the iv time from the onset of the flow to the peak velocity; $\vec{\sigma}$ and the ejection time (ET), which was defined as the time from the onset of the flow to the end of the flow (fig 1). Five sequential complexes were measured ${ }^{-}$

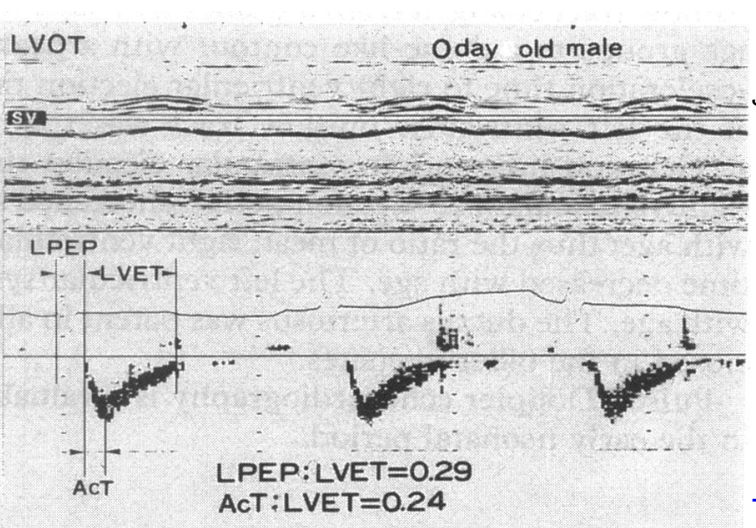

RPEP: $R$ VET $=0.49$

ACT: RVET $=0.26$
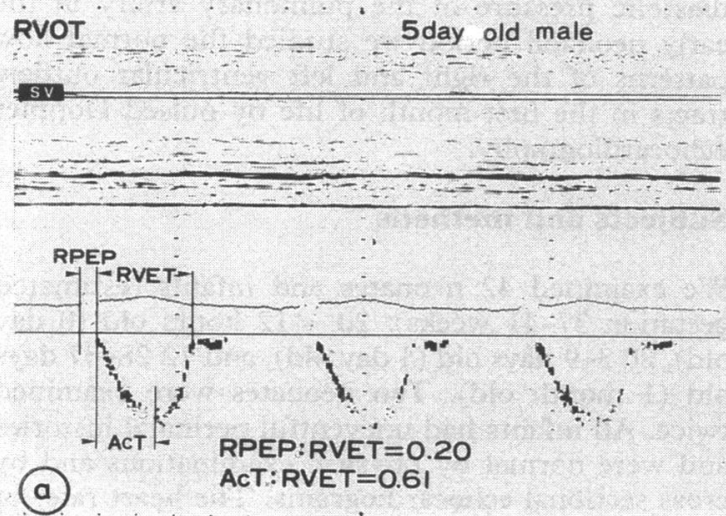

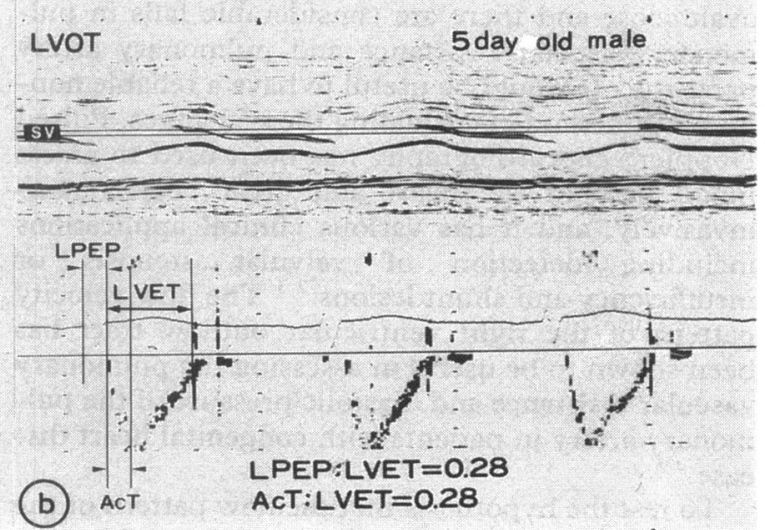

(b)

Fig 1 Pulsed Doppler echocardiogram obtained at the right ventricular outflow tract (RVOT) and left ventricular outflow tract ( $L V O T$ ) 0 and 5 days after birth. (a) The right ventricular outflow tract flow pattern changed from a triangular shape with a peak velocity in early systole (top) to a dome shape with a peak velocity in mid-systole (bottom). (b) The left ventricular outflow tract flow pattern was triangular with a peak velocity in early systole and did not change with increasing age. RPEP, right pre-ejection period; $R V E T$, right ventricular ejection time; AcT, acceleration time; LPEP, left pre-ejection period; LVET, left ventricular ejection time; $S V$, sample volume. 
Table Right and left systolic time intervals and $A c T: E T$ ratios at three ages (mean (SD))

\begin{tabular}{|c|c|c|c|}
\hline & $\begin{array}{l}0 \text { day }(2-12 \mathrm{hrs}) \\
(n=20, M / F=12 / 8)\end{array}$ & $\begin{array}{l}4 \text { day }(3-9 \text { days }) \\
(n=20, M / F=11 / 9)\end{array}$ & $\begin{array}{l}1 \text { month }(28-37 \text { days }) \\
(n=12, M / F=3 / 9)\end{array}$ \\
\hline Heart rate (beats/min) & $121(11)$ & $117(14)$ & $142(15)^{\star}$ \\
\hline $\begin{array}{l}\text { RPEP (ms) } \\
\text { AcT (ms) } \\
\text { RVET (ms) } \\
\text { RPEP:RVET } \\
\text { AcT:RVET }\end{array}$ & $\begin{array}{c}93.8(14.7) \\
68.7(16.7) \\
192.8(13.5) \\
0.51(0.12) \\
0.37(0.09)\end{array}$ & $\begin{array}{c}72.1(11.9)^{\star} \\
120.5(18.9)^{\star} \\
215.0(17.4)^{\star} \\
0.34(0.07)^{\star} \\
0.56(0.07)^{\star}\end{array}$ & $\begin{array}{c}64.3(5.8)^{\star} \\
101.0(20.8)^{\star} \\
200.6(16.0)^{*} \\
0.32(0.03)^{\star} \\
0.52(0.05)^{\star}\end{array}$ \\
\hline $\begin{array}{l}\text { LPEP (ms) } \\
\text { AcT (ms) } \\
\text { LVET (ms) } \\
\text { LPEP:LVET } \\
\text { AcT:LVET }\end{array}$ & $\begin{array}{c}76.9(13.1) \\
55.4(9.7) \\
204.3(21.5) \\
0.36(0.05) \\
0.27(0.04)\end{array}$ & $\begin{array}{c}78.4(11.0) \\
53.2(7.6) \\
194.9(16.6) \\
0.40(0.06) \\
0.27(0.04)\end{array}$ & $\begin{array}{c}69.8(7.5) \\
60.5(14.3) \\
189.4(14.4) \\
0.37(0.05) \\
0.30(0.03)\end{array}$ \\
\hline
\end{tabular}

RPEP, right pre-ejection period; RVET, right ventricular ejection time; AcT, acceleration time; LPEP, left pre-ejection period; LVET, left ventricular ejection time.

${ }^{\star} p<0.01$ compared with 0 day old neonates.

and averaged to obtain the final systolic time interval and AcT. PEP, AcT, and ET were determined in 12 recordings by one observer on two occasions. The intra-observer variability for PEP, AcT, and ET was $3 \%, 4 \%$, and $2 \%$ respectively. The ductal patency was also evaluated by means of diastolic forward flow at the pulmonary end of the ductus.

Data were expressed as mean (SD) and were compared with those of other groups by Student's unpaired $t$ test. A probability value $<0.01$ in the two tailed test was considered to be significant.

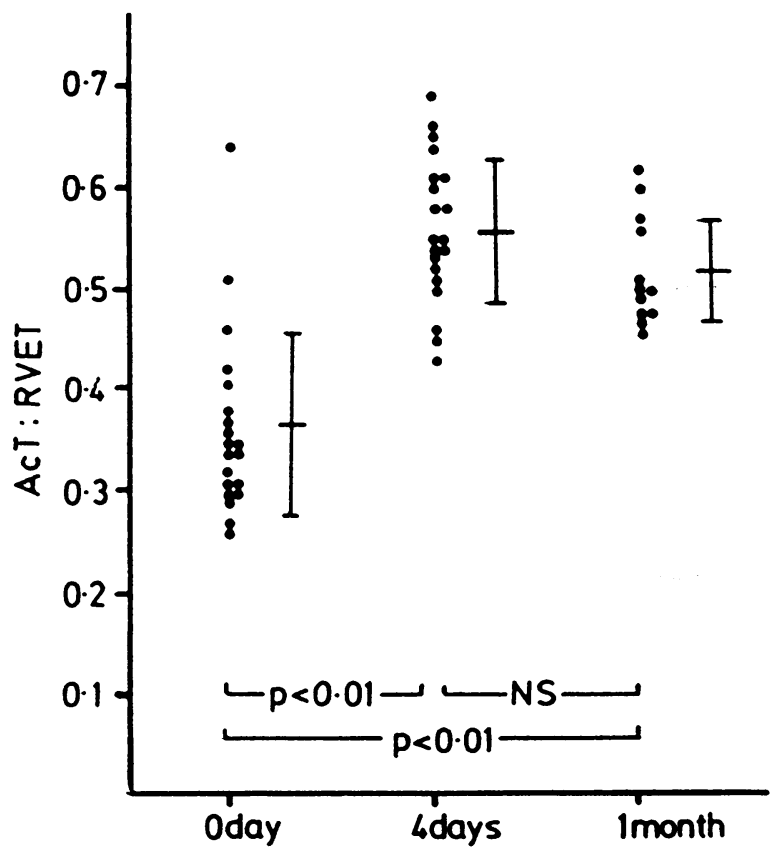

\section{Results}

FLOW VELOCITY PATTERN OF RIGHT AND LEFT VENTRICULAR OUTFLOW TRACT

The flow velocity pattern of the right ventricular outflow tract was initially triangular with a peak velocity in early systole; this changed to a domelike contour with a peak velocity in mid-systole (fig la).

The mean right ventricular AcT increased from a mean of $68.7 \mathrm{~ms}$ in the 0 day old neonates to

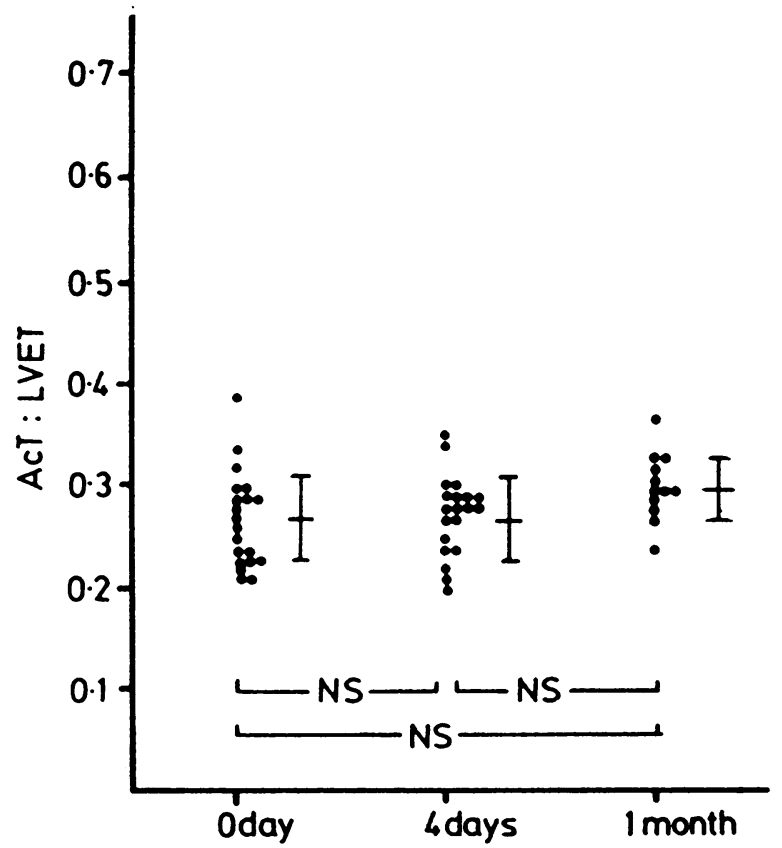

Fig $2 A c T: R V E T$ and $A c T: L V E T$ at three ages. AcT, acceleration time; RVET, right ventricular ejection time; LVET, left ventricular ejection time. Means (1SD) are shown. 
$120.5 \mathrm{~ms}$ in the 4 day olds and to $101.1 \mathrm{~ms}$ in the 1 month olds (table).

The mean AcT:RVET ratio increased significantly with age from 0.37 in the 0 day olds to 0.56 in 4 day olds and to 0.52 in 1 month olds (fig 2). None of AcT:RVET ratios was $<0.42$ in the older groups. In all 10 infants who were examined on two occasions the AcT:RVET ratio was higher at the second examination (fig 3 ).

The flow velocity pattern of the left ventricular outflow tract was also triangular with a peak velocity in early systole, but this pattern did not change with increasing age (fig $1 \mathrm{~b}$ ). The mean left ventricular AcT varied from 53.2 to $60.5 \mathrm{~ms}$ (table) and the mean AcT:LVET ratio varied from 0.27 to 0.30 (fig 2).

\section{RIGHT AND LEFT VENTRICULAR SYSTOLIC} TIME INTERVALS

Right ventricular systolic time intervals changed significantly with age (table). The right ventricular pre-ejection period (RPEP) decreased from a mean of $93.8 \mathrm{~ms}$ in the 0 day olds to $72.1 \mathrm{~ms}$ in the 4 day

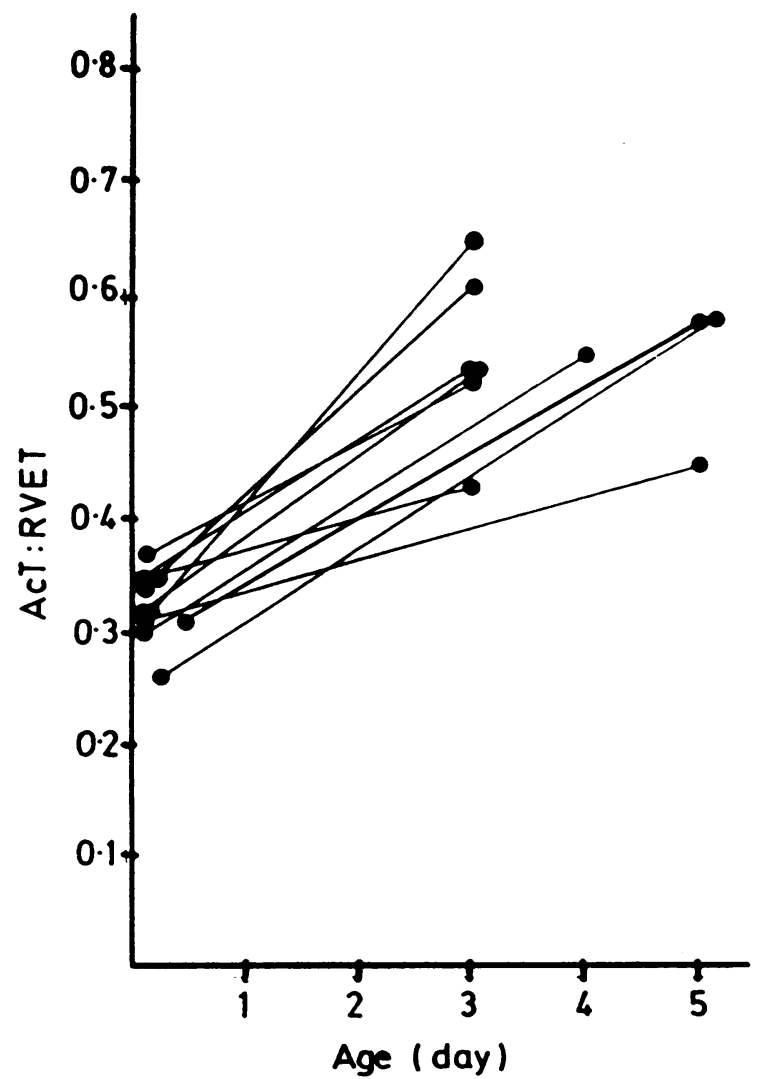

olds and to $64.3 \mathrm{~ms}$ in the 1 month olds.

The right ventricular ejection time (RVET) $\stackrel{\overrightarrow{\mathrm{s}}}{\text { ? }}$ increased from a mean of $192.8 \mathrm{~ms}$ in 0 day olds too $215.0 \mathrm{~ms}$ in 4 day olds and then decreased to $200.6 \mathrm{~ms}$ in the 1 month olds. The mean heart rate of 1 month olds was increased. The mean ${ }_{\circ}^{\Phi}$ RPEP:RVET ratio declined from 0.51 in 0 day olds to 0.34 in 4 day olds and to 0.32 in the 1 month olds (fig 4). A second examination in 10 neonates showed. a decreased RPEP:RVET ratio (fig 3).

Left ventricular systolic time intervals showed noo significant variation with age (table). The mean left? ventricular pre-ejection period (LPEP) varied from? 69.8 to $78.4 \mathrm{~ms}$ and the mean left ventricular ejectioni time (LVET) varied from 189.4 to $204.3 \mathrm{~ms}$. The $\vec{\sigma}$ mean LPEP:LVET ratio varied from 0.36 to $0.40^{-}$ (fig 4).

\section{PATENCY OF THE DUCTUS ARTERIOSUS}

Left to right shunt flow through the ductus was? detected with pulsed Doppler echocardiography in all 0 day old neonates, whereas none of the 4 day old or the 1 month old neonates had ductal flow.

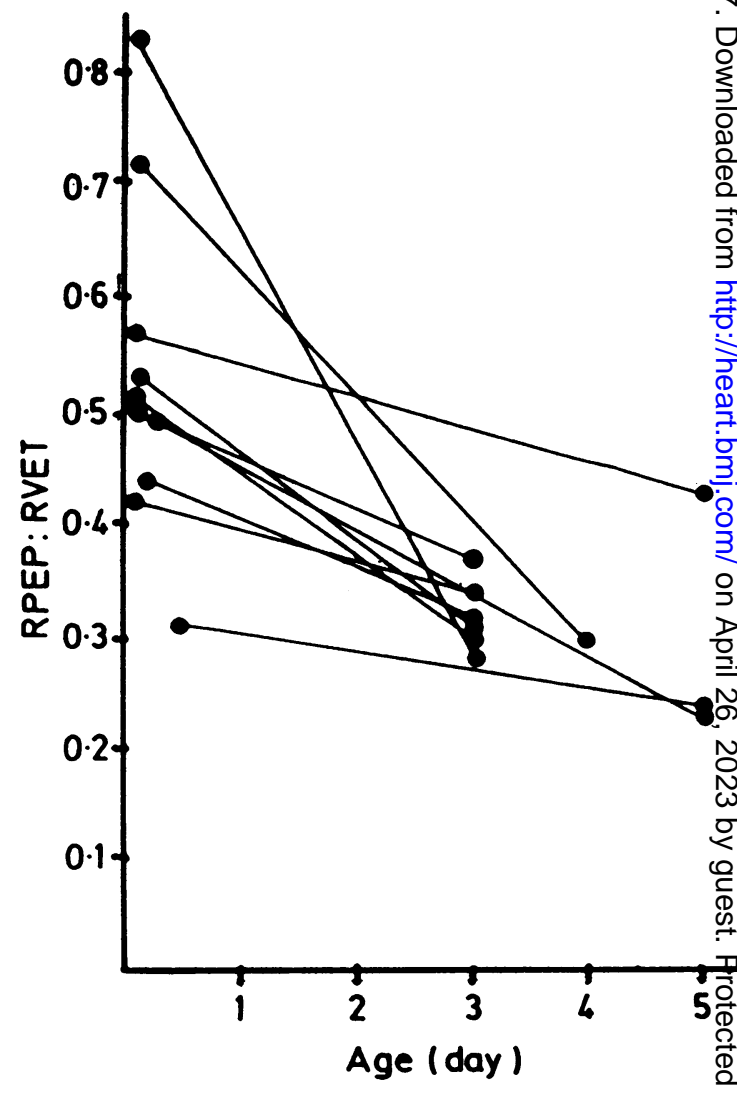

Fig 3 Sequential $A c T: R V E T$ and RPEP:RVET ratio in 10 neonates. $R P E P$, right pre-ejection period; $R V E T, \quad$ O right ventricular ejection time; $A c T$, acceleration time. 


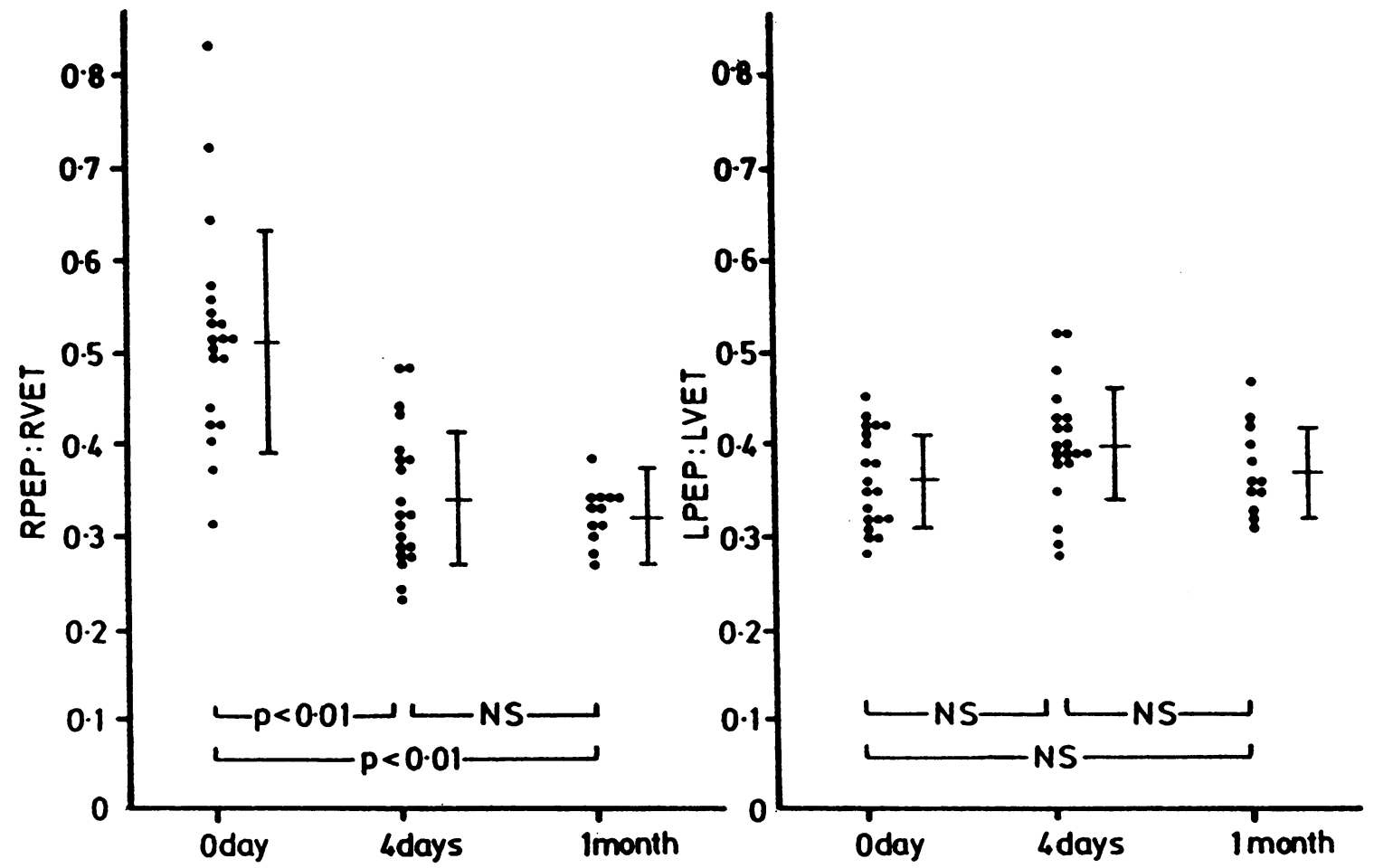

Fig 4 RPEP:RVET ratio and LPEP:LVET ratio at three ages. RPEP, right pre-ejection period; $R V E T$, right ventricular ejection time; LPEP, left pre-ejection period; LVET, left ventricular ejection time. Means (1SD) are shown.

\section{Dicussion}

$M$ mode and cross sectional echocardiograms have been widely used to evaluate cardiac function, ${ }^{8}$ to diagnose congenital heart diseases, ${ }^{9}$ and to assess the pulmonary vascular bed. ${ }^{1011}$ These non-invasive techniques are especially useful in neonates. Detailed pulsed Doppler echocardiographic studies of the haemodynamic status of normal or diseased neonates, however, have not been performed before.

We found that the shape of the flow velocity envelope of the right ventricular outflow tract in healthy infants changed considerably in the early neonatal period from a triangular shape to a domelike contour; this was confirmed by an increase in AcT:RVET ratio. We considered that an AcT:RVET ratio of $<0.42$ indicated the presence of pulmonary hypertension. This change may reflect a decrease of pulmonary artery pressure. ${ }^{1}$ The change in the AcT:RVET ratio is regarded as an indicator of pulmonary vascular resistance and pulmonary artery pressure in laboratory animals ${ }^{12}$ and patients with pulmonary hypertension. ${ }^{45}$ Franklin et al reported the pattern of right ventricular ejection as a gradual increase in flow with a rounded peak in mid-systole and that of the left ventricular ejection as an abrupt increase in flow with a sharp peak in early systole. As pulmonary artery resistance increases the ejection pattern of the right ventricle approaches that of the left ventricle. ${ }^{12}$ With pulsed Doppler echocardiography the flow velocity pattern of the right ventricular outflow tract in normal controls has a dome-like contour with a peak velocity in midsystole, whereas in patients with pulmonary hypertension the envelope is triangular with a peak velocity in early systole. ${ }^{45}$ Thus pulsed Doppler echocardiography may be used to detect raised pulmonary artery pressure. ${ }^{4}$ The rapid acceleration of the flow in the pulmonary artery appears to be caused by the increased peak $\mathrm{dP} / \mathrm{dt}$ of the pressure load of each ventricle, ${ }^{13}$ and the early deceleration of the flow appears to be caused by the high total pulmonary vascular resistance and increased pulmonary vascular impedance. ${ }^{14}$ Okamoto et al reported that the triangular envelope of the flow pattern is a specific feature of the pulmonary ejection in patients with pulmonary hypertension. ${ }^{4}$ Kitabatake et al examined the flow velocity pattern in the right ventricular outflow tract in adults with pulmonary hypertension and found that AcT or AcT:RVET 
decreased as pulmonary artery pressure increased. ${ }^{5}$

Pulmonary artery pressure has been evaluated from the flow pattern obtained at the main pulmonary artery by pulsed Doppler echocardiography. ${ }^{15}$ The flow in the main pulmonary artery in the early neonatal period is likely to be affected by the shunt flow through the ductus arteriosus. This is why we used the flow pattern of the right ventricular outflow tract to assess the pulmonary vascular bed.

Cardiac catheterisation in normal infants has shown that pulmonary artery pressure is high soon after birth and gradually falls in the first days of life. ${ }^{1}$

Variables other than these direct measurements have been used to assess the pulmonary vascular bed non-invasively. The systolic time interval, which appears to be influenced by factors such as afterload, myocardial contractility, ventricular electrical activation, preload, or heart rate, ${ }^{16}{ }^{17}$ is one of the noninvasive variables that has been used to evaluate cardiac function and the pulmonary vascular bed. ${ }^{18} \mathrm{We}$ used pulsed Doppler echocardiography to measure the systolic time intervals of the right and left ventricles. There was a clear decline of absolute RPEP and RPEP:RVET ratio in the early neonatal period. These findings are compatible with the previous reports in which $M$ mode echocardiography was used. ${ }^{10}$ Our method determines the onset and the end of the ejection more accurately. The preejection period of each ventricle was, however, longer in our study. The time lag between sampling and frequency analysis was probably responsible for this. ${ }^{7}$ Riggs et al obtained serial $M$ mode echocardiograms from normal full term infants and measured right ventricular systolic time intervals from the pulmonary valve echo. ${ }^{10}$ They showed that alterations in the RPEP:RVET ratio reflected the decreasing pulmonary artery pressure and pulmonary vascular resistance in the early neonatal period.

Another important aspect in our study is the assessment of the patency of the ductus arteriosus. In all the 0 day olds there was forward flow at the pulmonary end of the ductus during diastole indicating patency of the ductus. No forward flow was detected in older neonates. Pulsed Doppler examination in combination with cross sectional echocardiography is a non-invasive and highly sensitive method of evaluating the patency of the ductus arteriosus. ${ }^{1920}$ The ratio of LPEP:LVET was slightly but not significantly lower in the 0 day old neonates. This might be the result of increased preload and decreased afterload of the left ventricle caused by the left to right shunt through the ductus arteriosus. Pulmonary artery pressure did not fall abruptly after the establishment of respirationdespite a considerable decrease in the pulmonary vascular resistance. ${ }^{1}$ We did not measure the shunt? through the ductus; however, an increase in pulmonary blood flow caused by the left to right shune may have influenced pulmonary artery pressure anc pulmonary vascular resistance in the neonates who? were $<12$ hours old.

We thank Professor T Tamada, Dr S Konuma, and their associates at the Department of Obstetrics and $\vec{\omega}$ Gynaecology, Jichi Medical School Hospital, for their valuable cooperation.

\section{References}

1 Adams FH. Fetal and neonatal circulations. In: Adams FH, Emmanouilides GC, eds. Heart disease in infants, children and adolescents. Baltimore: WilliamsT and Wilkins, 1983:11-7.

2 Pearlman AS, Lighty GW Jr. Clinical applications of two-dimensional/Doppler echocardiography. Car diovasc Clin 1983;13:201-22.

3 Stevenson JG. Doppler evaluation of common shunto lesions in congenital heart disease. In: Nanda NC, ed. Doppler echocardiography. New York and Tokyo. Igakushoin, 1985:393-415.

4 Okamoto M, Miyatake K, Kinoshita N, Sakakibara H Nimura Y. Analysis of blood flow in pulmonary? hypertension with the pulsed Doppler flowmeter combined with cross sectional echocardiography. $B P$ Heart $\mathcal{F}$ 1984;51:407-15.

5 Kitabatake $A$, Inoue $M$, Asao $M$, Masuyama $T$, Tanouchi J, Morita T. Noninvasive evaluation of pulmonary hypertension by a pulsed Doppler technique? Circulation 1983;68:302-9.

6 Matsuo H, Morita H. Current status of pulsed Dopplen method. f Cardiogr 1984;14(suppl II):27-39. (In Japanese.)

7 Sanada J, Nakamura K, Minami Y, et al. Pulsed. Doppler echocardiographic assessment of mitraß regurgitation. fpn $\mathcal{F}$ Med Ultrasonics 1983;10:5-13.尹 (In Japanese.)

8 Gutgesell HP, Pinsky WW, Duff DF, Adams J, McNamara DG. Left and right ventricular systolic times intervals in the newborn: usefulness and limitation in?. distinguishing respiratory disease from transposition 0 of the great arteries. Br Heart $\mathcal{F}$ 1979;42:27-34.

9 Macartney FJ. Cross sectional echocardiographic diag 0 nosis of congenital heart disease. Br Heart Æ 1983;50:501-5.

10 Riggs T, Hirschfeld S, Bormuth C, Fanaroff A, Lieb man J. Neonatal circulatory changes: an echo $\frac{-}{0}$ cardiographic study. Pediatrics 1977;59:338-44.

11 Riggs T, Hirschfeld S, Fanaroff A, et al. Persistence of fetal circulation syndrome: an echocardiographif study. I Pediatr 1977;91:626-31.

12 Franklin DL, Van Citters RL, Rushmer RF. Balance? between right and left ventricular output. Circ Re⿻ 1962;10:17-26. 
13 Gleason WL, Braunwald E. Studies on the first derivative of the ventricular pressure pulse in man. $f$ Clin Invest 1962;41:80-91.

14 Reuben SR. Compliance of the human pulmonary arterial system in disease. Circ Res 1971;29:40-50.

15 Kosturakis D, Goldberg SJ, Allen HD, Loeber C. Doppler echocardiographic prediction of pulmonary arterial hypertension in congenital heart disease. $A m$ f Cardiol 1984;53:1110-5.

16 Weisser AM, Lewis RP, Leighton RF. The systolic time intervals as a measure of left ventricular performance in man. In: Yu PN, Goodwin JF, eds. Progress in cardiology. Philadelphia: Lea and Febiger, 1972:155-83.

17 Leighton RF, Weissler AM, Weinstein PB, Wooley
CF. Right and left ventricular systolic time intervals -effect of heart rate, respiration and atrial pacing. Am $\mathcal{Y}$ Cardiol 1971;27:66-72.

18 Hirschfeld S, Meyer R, Schwartz DC, Korfhagen J, Kaplan S. The echocardiographic assessment of pulmonary artery pressure and pulmonary vascular resistance. Circulation 1975;52:642-50.

19 Huhta J, Cohen M, Gutgesell HP. Patency of the ductus arteriosus in normal neonates: twodimensional echocardiography versus Doppler assessment. I Am Coll Cardiol 1984;4:561-4.

20 Gentile R, Stevenson JG, Dooley T, Franklin D, Kawabori I, Pearlman A. Pulsed Doppler echocardiographic determination of time of ductal closure in normal newborn infants. $\mathcal{F}$ Pediatr 1981;98:443-8. 